\title{
SENTIDO Y ESTRUCTURA DE JUAN JOSÉ, DE JOAQUÍN DICENTA
}

José Servera Baño y Patricia Trapero Universidad de las Islas Baleares

La escasa critica que se ha preocupado por la obra dramática Juan José (1895), de Joaquín Dicenta coincide en singularizarla mediante dos elementos caracterizadores de la estructura y la temática: drama de honor y drama social. Se afirma que la obra tiene la estructura del drama de honor propio del Siglo de Oro español e incorpora la problemática social. El protagonista de Juan José es el representante de la clase sociaí obrera, que tiene conciencia de clase y asume su sentimiento de honor, si no igual al de la nobleza, muy próximo a él. Por lo tanto, es la incorporación de lo «social» lo que diferencia Juan José del drama de honor del siglo XVII.

\section{EL TEMA DE HONOR}

Una aproximación a la definición y a los componentes del drama del honor nos facilitará las diferencias y coincidencias con Juan José.

Sobre el origen del concepto de "honor u honra", como concepto de arraigo medieval son imprescindibles los estudios de Sánchez Albornoz ${ }^{l}$ y de Menéndez $\mathrm{Pidal}^{2}$, quien constata la singularidad que adquirió dicho tema en nuestra escena.

Eduardo Forastieri ${ }^{3}$ resume los origenes del concepto de la honra ba-

España: un enigma histórico, Buenos Aires, Sudamérica, 1956.

- De Cervantes y Lope de Vega, Madrid, Espasa-Calpe, Col. Austral 120, 1940.

"Aproximación estructural al teatro de Lope de Vega, Madrid-Miami-New York-San Juan, Hispanova, 1976. 
sándose en las aportaciones de Menéndez Pidal sobre los testimonios del derecho visigótico consuetudinario, las codificaciones de los Fueros. Partidas y Recopilaciones; Otis Green ${ }^{4}$ sobre el código caballeresco; Lida de Malkiel $^{5}$ sobre los ideales clásicos de la fama; Américo Castro ${ }^{6}$ sobre la obsesión por la limpieza de sangre, aspecto polémico que ha originado bastantes controversias, enfoques y estudios, entre los que destacamos los de Bataillon y Rodríguez Puértolas ${ }^{8}$.

Díez-Borque define el honor como el "principio de una sociedad estamental con dominio de los estamentos privilegiados». Dicho sentimiento es exclusivo de la nobleza, aunque hay posibilidad de transmitirlo a los vasallos. El honor - seguimos a Diez-Borque- es respeto, estima acordada a la virtud o al alto rango a la dignidad; por extensión, es una marca o signo de reconocimiento que un hombre tiene de sus altas cualidades. La asimilación del honor a la reputación determina que el honor no dependa de su propietario, sino de la opinión de los demás. Aubrun sintetiza la idea: «El honor para consigo (honor) suscita dos móviles: la preocupación por el buen nombre personal (fama) y la preocupación por el honor familiar (honra), que, por otra parte, se confunden frecuentemente) ${ }^{10}$.

Existe toda una teorización sobre los conceptos básicos: honor y honra. Ricart ${ }^{11}$ distingue entre el "honor se posee y se defiende mientras la honra se recibe y es debida». El honor «es», la honra se "mueve» en la sociedad y puede ser poseida por todos como reflejo de la opinión y no como virtud aislable ${ }^{2}$. Sin embargo, como señala Forastieri ${ }^{13}$, Sebastián de Covarrubias (Tesoro de la lengua castellana o española) afirmaba que (honor vale lo mismo que honra", con tal opinión simplificariamos todas las matizaciones y diferenciaciones terminológicas que a veces sólo llevan a confusión, aunque parece bastante probable que el español de aquella época distinguiera perfectamente entre la virtud como cualidad intrínseca del individuo y honra como admisión ajena de esta virtud.

El honor está unido al linaje. La cuna está por encima de la virtud adquirida. Pero, en la comedia, al honor se une el derecho de toda persona

${ }^{4}$ España y la tradición occidental, Madrid, Gredos, 1969.

"La idea de la fama es la Edad Media castellana, México, F.C.E., 1953.

- De la edad conflictiva, Madrid, Taurus, 1972.

" "La desdicha por la honra: génesis y sentido de una novela de Lope» en Varias lecciones de clásicos españoles, Madrid, Gredos, 1964.

" "El campesino en la comedia del Siglo de Oro" en De la edad media a la edad conflictiva, Madrid, Gredos, 1972.

9 Sociologia de la comedia española del siglo XVII, Madrid, Cátedra, 1976, p. 297.

16 La comedia española 1600-1680. Madrid, Taurus, 1968, p. 239.

" "El concepto de la honra en el teatro del Siglo de Oro y las ideas de Juan Valdés" Segismundo, 1, 1965, pp. 43-69.

${ }_{12}$ Díez-Borque: op. cit. p. 298.

13 Aproximación estructural al teatro de Lope de Vega, p. 61. 
buena a la dignidad, autorrespeto y respeto de los demás, así todos los estratos sociales se ven afectados en su comportamiento por este sistema de valores, aunque hay que distinguir, siguiendo a Gustavo Correa ${ }^{14}$ un honor vertical - referencia a la dignidad estamental del individuo-y un honor horizontal - referencia a la dignidad de toda persona honrada-.

La honra es un bien comparable a la vida y se defiende hasta la muerte. De tal manera que se impone una formalización de un código que regirá con una normativa precisa todo un comportamiento social. Unido a este riguroso comportamiento social, cabe destacar la relación entre el honor y la "pureza de sangre», tema estudiado principalmente por Américo Castro y retomado por Forastieri, quien recoge un documento de los primeros años del reinado de Felipe III que Kamen ${ }^{15}$ y Noël Salomon ${ }^{16}$ también citan:

\begin{abstract}
Porque en España hay dos géneros de noblezas. Una mayor que es hidalguía y otra menor, que es la limpieza, que llamamos christianos viejos. Y aunque la primera es más honrado de tenerla; pero muy más estimamos a un Hombre Pechero y limpio, que a un Hidalgo que no es limpio"t.
\end{abstract}

Sin embargo, es importante el hecho de que Salomon relacione dicho problema - antisemitismo-- con el de la lucha de clases, cuestión que incide directamente en Juan José, donde evidentemente no se plantea el problema del antisemitismo, pero sí el de la lucha de clases a través del sentido del honor. Es curioso que la afirmación de Salomon respecto a Lope sea válida para Dicenta con mucha mayor claridad, ya que confirma que en el trasfondo del antisemitismo late una problemática de lucha de clases.

No hay duda sobre la omnipotencia del honor como motivo determinante de acción y pensamiento. En la comedia de Lope, honor y honra, son dos conceptos clave que rigen, valoran y condicionan la actuación de los individuos. Y en el caso de Juan José parece ser que se cumple dicha regla, y tal vez se añada un romántico halo de fatalidad, que también se da en el drama de honor del Siglo de Oro como fuerza determinante de la acción que conducirá al protagonista o a su rival a la destrucción. La presiones sociales rigen la conducta de los personajes, que quedan en los presupuestos de la sociedad sin poder superar la situación límite a la que son llevados. 199.

14 «El doble aspecto de la honra en Peribánez», Hispanic Review, XXVI, 1958, pp. 188-

is La Inquisición española, Madrid, Alianza, 1973.

16 Recherches sur le theme paysan dans "Comedia" au temps de Lope de Vega. Institut d'Etudes Ibériques et Ibéro-americaines de L'Université de Bordeaux, 1965.

${ }^{17}$ Forastieri: $o p$. cit., p. 81 . 
Algunos autores (Maravall, Díez-Borque) plantean que la comedia no refleja exactamente la problemática real del honor en la sociedad de aquel tiempo, ya que la comedia (sería un tema de propaganda al servicio de los intereses de la sociedad monárquico señorial, porque supone respetar al extremo las leyes de un sistema social, aceptando la figura estamental antes que el interés personal»" ${ }^{18}$. Asimismo apunta Aubrun: “Convención social o convención dramática? ¿Es verosimil que la teoría general, tal como se ejemplifica en las tablas, haya suscitado cierta práctica de ella en la calle?») ${ }^{19}$.

En Juan José, tanto el honor vertical (aquí plasmado en el señorito Paco) como el honor horizontal (el honor que ha adquirido honradamente y con su trabajo Juan José) se plantean como exponentes de la lucha de clases. El personaje Juan José vive para el honor y se conduce hacia las resoluciones más drásticas que le dicta el honor a un final trágico que obedece a una solución fatalista del conflicto. Pero la gran diferencia en Juan José con los dramas de honor del siglo XVII consiste en la poca insistencia en la palabra «honor u honra», que tanto se reitera en aquellos dramas. Sin duda la preocupación por el honor del protagonista se deduce de sus acciones, no de su única alusión al concepto:

y piensan que ella cederá, que yo bajaré la cabeza, porque el hambre es mal consejero del querer y la miseria mala compañera de la honra ${ }^{20}$.

que Dicenta relaciona con otros condicionantes, sin duda surgidos de las ideas sociales de la incipiente izquierda política de la época. Por otra parte, son el orgullo y la conciencia social del personaje ideas recurrentes en la obra, ya que la situación inicial del protagonista le niega cualquier mínima posibilidad de honorabilidad de cuna y de ascenso social.

La venganza, otro de los elementos básicos del drama de honor, es la resolución final de Juan José, aunque en el drama de Dicenta la reparación del honor, a través de la venganza, no implique una superación de la situación, sino, por el contrario, el desenlace del conflicto supone el definitivo agravamiento final de una tragedia. Este final implica el castigo del protagonista (que ha pasado de ser víctima a agresor) y contrasta fuertemente con los finales tópicos de las comedias del siglo XVII, como en el caso de $\mathrm{El}$ médico de su honra de Calderón, donde aun siendo inocente la víctima doña Mencía, su asesino y marido, don Gutierre, no es castigado por el Rey, sino

17 Diez-Borque: op. cit., p. 299.

19 Aubrun: op. cit., p. 240.

20 A partir de ahora nos referiremos a las páginas de la edición de Dicenta: Juan José, Madrid, Cátedra, 1982, indicándolas así: (JJ, p. 112.) 
premiado con otra esposa, doña Leonor. Todo ello demuestra que el honor es una cuestión social. Y así también se manifiesta en Juan José, cuyo protagonista sustenta su relación amorosa en los pilares de la lealtad y mutua correspondencia, y, así, mediante la configuración «leal» de Juan José frente a la "desleal» de Rosa se ofrece una visión positiva del protagonista masculino frente a la actitud versátil de la protagonista femenina.

Si el honor en el Siglo de Oro depende de la cuna, del «status» social, también en Juan José ocurre lo mismo. En este sentido, la dialéctica del honor-honra/deshonor-deshonra es idéntica. Juan José se configura con las acciones propias de cualquier protagonista del drama del honor del Siglo de Oro. Inicialmente tiene fe ciega en su amada, pero las evidencias de la transgresión de la amada respecto al pacto de fidelidad de la pareja, a pesar de que no se hayan casado, le sitúan en la duda y con la comprobación posterior (en el caso de Juan José no hay lugar a dudas) de la transgresión, impone una justicia que lava su afrenta. En el caso de Juan José la solución es extrema, el asesinato pasional. Si en el drama de honor del siglo XVII se establece una lucha dentro del propio estamento, la nobleza, aunque a veces los rangos dentro del mismo estamento marquen distinta gradación de poder, en Juan José la lucha se establece entre dos clases sociales distintas: burguesía (Paco) y proletariado (Juan José).

El personaje Juan José desde el principio tiene un «honor», una «fama» y una propia consideración sobre sí mismo, muy manifiesta en el orgullo y en la conciencia de clase social, además su caracterización se basa en la fama, es decir, en la buena consideración ajena, incluso de sus enemigos de clase, pero sobre todo, de sus propios compañeros. Lo que intenta conseguir Paco, es decir, el amor de Rosa, es un ataque a la "honorabilidad, honra y fama» de Juan José, aunque tal vez la motivación de Paco no sea ésta, sino simplemente la de querer a Rosa, por ello la acción final de Juan José debe entenderse como una restitución de aquéllas. Pero, al ser dicho personaje el exponente de una clase social, se trata de una restitución diferente a las que suceden en el teatro de honor del Siglo de Oro, basadas en el honor individual de un sujeto, mientras que aqui se restituye el honor de una clase social, el proletariado. Esta dinámica deja al descubierto los condicionantes que conducen al protagonista a esa trágica situación límite.

\section{EL TEMA SOCIAL}

Es evidente que en Juan José el honor determina el pensamiento y la acción del drama; las presiones sociales conducen al desenlace fatal y, en este caso, a la destrucción de los personajes que configuran el triángulo 
amoroso. Sin embargo, como afirma Jaime $\mathrm{Mas}^{21}$, más que propiamente un drama de honor parece un drama convencional de amor, pasión y celos, en el que predomina la severa estructura dramática externa típicamente calderoniana, pero en el que la unidad dramática interna lo forma el enfrentamiento de clases, el conflicto y la justicia social. Pensamos, al respecto, que la crítica, en general, olvida esta última condición del drama, decantándose muy ligeramente por contemplar la obra como mero conflicto individual, dentro de una línea dramática lopesca. Por el contrario creemos que el hambre y el paro, es decir, los condicionantes sociales son los móviles básicos que generan la acción del drama, tal como señala también García Pavón ${ }^{22}$, por lo que disentimos de Ruiz Ramón ${ }^{23}$ al considerar lo social como un simple elemento de la caracterización de los personajes y de la acción de la trama, ya que - arguye - no encontramos en la obra una protesta ni denuncia, ni las causas de la situación en que halla el obrero. Tal vez sea aquí oportuno reproducir dos párrafos de la obra:

PERICO.--iHay que echarse a la calle y acabar con el hato de granujas que nos oprime! (JJ. p. 73.)

Más adelante el propio Juan José:

... iNi que el trabajo fuese una limosna pa que a uno se lo nieguen!... Pues qué, ¿no hay más que condenar a un hombre a morirse de hambre o a pedir por Dios?... ¿Hay en esto justicia? Y si no la hay, ¿por qué sucede? ¡Luego dicen que si los hombres matan y roban!... iQué van a hacer! (JJ, p. 121.)

Son palabras reveladoras de la conciencia social del protagonista, el cual no sólo se opone a la figura del burgués Paco, sino también a la de los obreros no concienciados, como son Andrés y otros que pululan por la taberna, excepto Perico. El afán de Dicenta por ofrecer un cuadro verosímil de las distintas actitudes del proletariado le lleva a dibujarnos las diferentes opciones de los personajes que componen la clase social proletaria, obteniendo un efecto realista. Así aparecen los distintos tipos de obrero: el con-

21 Edición y estudio de Dicenta: Juan José, Madrid, Cátedra, 1982.

22 Teatro social en España, Madrid, Taurus, 1962.

${ }^{23}$ "Joaquin Dicenta y la aurora del drama social" en Historia del Teatro Español, Madrid, Alianza, 1967. 
cienciado (Juan José, Perico), el inhibido y escéptico (Andrés, Ignacio), que a su vez se configuran mediante matizaciones: uno cree en la libertad como gran valor social, otro en la justicia; uno se inhibe bebiendo, etc... Por lo tanto, el personaje comprometido de Juan José se realza en su contraposición con los que le envuelven y adquiere así un significado específico en la obra.

La incorporación de la problemática social supone un gran paso para el teatro de la época. Las valoraciones peyorativas de la obra basándose en la supuesta repetición del esquema lopesco nos parecen superfluas e ignorantes de lo que supuso la obra. Sirva como ejemplo la negativa de actores afamados a representar la obra y también el análisis de Jaime Mas sobre el ambiente, estreno y su repercusión en distintas clases sociales (fracaso para el público burgués/éxito para las capas populares de la sociedad).

Detectar que la estructura de Juan José tiene similitudes con el drama de honor del siglo XVII, no puede hacernos ignorar la importancia de lo social en esta obra. No creemos en la primacia de un aspecto sobre otro, por el contrario creemos que esa simbiosis de elementos particulariza la obra y la diferencia del drama propiamente de honor y también del posterior teatro social e incluso del teatro romántico y melodramático. Parece incuestionable que la conflictividad de la obra en aquella época surgió a partir de las consideraciones sociales de la obra, y no, desde luego, de la estructura lopesca. Aunque ésta contribuyera al éxito de público, tal como apunta Joan Estruch Tobella ${ }^{24}$.

\section{Un ANTECEDENTE INMEDIATO: «TeRESA» DE ClaríN}

A esta valoración de la obra según «horizonte de expectativas» hay que añadir lo que supone la obra literaria. Ese mismo año de 1895 , unos meses antes, se estrena Teresa de Clarin, drama en un acto que suele considerarse el antecedente inmediato de Juan José. En nuestra opinión, desde un punto de vista estructural, nada le adeuda una a la otra, y desde luego Juan José es una obra de mayores pretensiones y logros. La única coincidencia estriba en la temática social y en algunos detalles como por ejemplo el común ambiente de taberna, o la referencia a la honra del pobre:

${ }^{24}$ Joan Estruch Tobella: «La Teresa de Clarín, un intento fracasado de renovación del teatro español», en Segismundo, n. ${ }^{\circ}$ 37-38, Madrid 1983, p. 109. 
RंoQuE.--Tu señorito será un ángel, pero es un señorito, un miserable, como todos, que no creerá en la honra del pobre... ${ }^{25}$.

El concepto de la honra es mucho más insistente en Teresa, pues aparece en más de media docena de ocasiones, sólo reproducimos un par:

\footnotetext{
Teresa.-... piensa, y no se trata de que tenga razón sino de que lo piensa, y aquí es el amo, que de los señores no puede venir nada que no manche, que no deshonre si no se le arranca la justicia del pueblo.

porque, en rigor, ¿qué más tiene él que la honra que yo le guardo? (T., p. 96.)

ROQUE.-... ¿Qué salga ese cobarde, ese burgués maldito, que no cree!, ¡cómo ninguno cree!, en la honra de los pobres. (T., p. 107.)
}

En la obra de Clarín también se trata el típico triángulo amoroso, aunque no se desarrollen estructuralmente todas las posibilidades y la acción quede cercenada, presentándonos exclusivamente un cuadro, una secuencia, una pequeña reflexión sobre dicha temática, frente al gran despliegue que supone Juan José.

\section{LA ESTRUCTURA DE «JUAN JOSE̋"}

Un desmenuzamiento de actos, cuadros y escenas de Juan José nos descubrirá algunos aspectos relacionados con el tipo de estructura de la obra:

\section{Acto I}

\section{Planteamiento}

Escenas 1, 2, y 3: Nos introduce en un ambiente proletario: taberna. La controversia política es una expectativa dramática que, como tal se pierde,

\footnotetext{
${ }^{25}$ Nos referiremos a las páginas de la obra de Clarín, Teresa, en la edición de L. Romero en la editorial Castalia, Madrid 1976, de la siguiente forma: (T., p. 81.)
} 
ya que en 1, 2 se plantea el conflicto amoroso Juan José-Rosa y Juan JoséRosa-Paco, donde se nos ofrece una serie de informaciones respecto a: 1) comportamiento de Rosa (en oposición al personaje de Toñuela); 2) relaciones Juan José-Rosa (en una especie de Feed-back); 3) insinuación relaciones Rosa-Paco; 4) intermediaria (Isidra).

\section{Desarrollo}

Escena 4: Confirmación de la situación inicial: conflicto amoroso manifiesto en los celos de Juan José, esencial en el desarrollo de la obra. Amplificaciones: $1 .^{a}$ ) diálogo sobre Rosa; ${ }^{a} .^{a}$ ) historia de la vida de Juan José; que se manifiestan en una oposición de actitudes de los personajes: Juan José-Rosa y Andrés-Toñuela.

Escenas 5 y 6: Aparición y actuación de Isidra, así como la antipatía que este personaje suscita entre el resto de caracteres dramáticos.

Escena 7: Inicio real del conflicto con la presencia de Paco en la taberna.

Escenas 8 y 9: Presencia de Rosa y Toñuela, quejándose de su situación laboral, que, posteriormente, derivará hacia lo afectivo.

Escenas 10 y 11: Encuentro entre Rosa y Paco.

Escenas 12, 13, 14 y 15: Enfrentamiento entre Paco y Juan José, con I, 14 como centro del conflicto dramático de dicho enfrentamiento y I, 15 como resolución inmediata y aparente de este primer choque.

\section{ACTO II}

Escenas 1 y 2: Presentación de una nueva situación: despido común. Es la consecuencia de 1,15. Isidra empieza a desplegar su estrategia con Rosa.

Escenas 3 y 4: Reflexiones sobre lo que ha pasado entre Rosa, Isidra y Toñuela. Luego Andrés e Ignacio.

Escena 5: Intervención celestinesca de Isidra.

Escena 6: Descubrimiento de sus mañas por Juan José, quien plantea la expectativa dramática de la cárcel (Acto III), manteniendo un segundo «enfrentamiento" con Paco a través de Isidra.

Escena 7: Enfrentamiento entre Rosa y Juan José.

Escena 8: Intervención sosegadora de Toñuela y Andrés y conclusión del segundo enfrentamiento con Paco (ausente).

Escena 9: Situación desesperada y meditación de una posible solución por parte de Juan José. 
Cuadro 1.

Escena 1: Planteamiento nueva situación: cárcel e información sobre lo ocurrido.

Escena 2: Plan de huida de Cano y rechazo por parte de Juan José.

Escenas 3 y 4: Misiva de Andrés a Juan José: información de la relación entre Rosa y Paco. Juan José decide fugarse (una acción que no interesa reflejar dramáticamente y que es, tan sólo, insinuada por la aparición de Juan José en casa de Paco en el Cuadro 2. ${ }^{\circ}$ )

\section{Desenlace}

Escenas 5 y 6: Monólogo-reflexión y determinación de la venganza. Escenas de situación inicial del desenlace.

Cuadro 2.

Escenas 1, 2 y 3: Situación económica pudiente de Rosa-Paco.

Escena 4: Inicio enfrentamiento entre Rosa y Juan José.

Escena 5: Enfrentamiento entre Rosa y Juan José.

Escena 6: Asesinato de Paco.

Escena 7: Asesinato de Rosa, a través del cual se autodestruye Juan José.

Escena 8: Conocimiento público de los hechos mediante la presencia de Andrés y confirmación del final trágico de Juan José.

Los dramas de honor del Siglo de Oro suelen plasmarse en: $\left.1^{\circ}\right)$ un planteamiento breve, $2 .^{\circ}$ ) un desarrollo amplio y $3 .^{\circ}$ ) un desenlace precipitado; sin coincidir necesariamente con cada uno de los actos. De esta manera Juan José sigue esta estructura básica si bien va acompañada por un enfoque diferente del desarrollo del argumento en cada una de sus partes: 1) Planteamiento breve del conflicto amoroso (tres primeras escenas), 2) Desarrollo amplio donde se plantea el conflicto de honor sin que haya procesos marcados de los personajes, ya que éstos son totalmente estáticos y estereotipos, 3) Desenlace en escenas relativamente cortas, acciones rápidas y, en cierta medida, esperadas. 
Igualmente una aplicación estructural como la propuesta por Brémond ${ }^{26}$ puede proveernos de una estructura desde dos perspectivas: la temática del honor padecida por Juan José y los factores sociales que se manifiestan en la obra, es decir, el cielo o proceso de la obra nos enseña que la degradación material de Juan José es paralela a la de su honor, con lo cual se corrobora la lectura de que lo «social» en la obra no es simplemente un fondo en el que se desarrolla una tragedia de amor y celos: $1 .^{\circ}$ ) Una situación inicial (celos de Juan José y pobreza). 2.. ) Una agresión del antagonista (flirteos de Paco y Rosa con posterior unión y pérdida de trabajo de Rosa y Juan José). 3. ${ }^{\circ}$ ) Superación de la agresión por parte de la víctima que se convierte en agresor (cronológicamente cárcel y crimen pasional).

La reducción de los personajes en el drama de Dicenta, respecto a los dramas de honor del siglo XII, implica una reducción del conflicto y la ausencia del típico enredo. Incluso podría establecerse un paralelismo en cuanto a enredo amoroso, discordias sociales y tratamiento de personajes, no así referente al tema de la honra, con la "commedia dell'arte» italiana ${ }^{27}$, aunque insistiendo en la extrema movilidad de sus tipos con respecto a los dramas del Siglo de Oro, con el fin de determinar una nómina de personajes:

Juan José Drama de honor Función comin Comedia dell'arte

Rosa dama/s objeto de discordia

enamorados

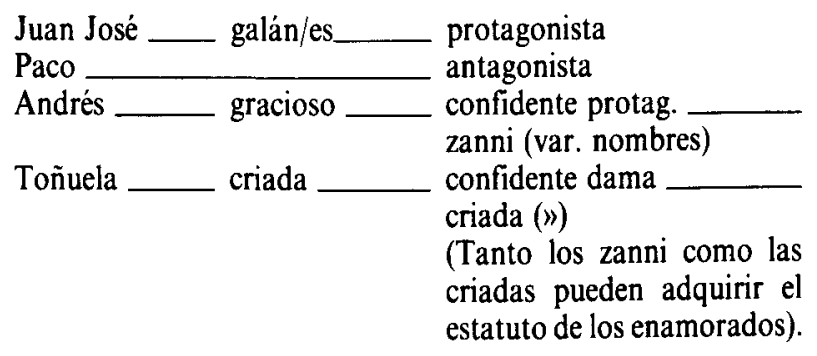

rey

padre

poderoso

villano

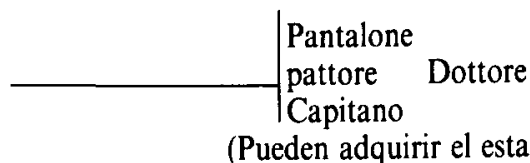

1

Isidra mediadora (celestina)

${ }^{26}$ "La lógica de los posibles narrativos» en Análisis estructural del relato, México, Premia Editora, 1982.

${ }^{27}$ Nicoll, Allardyce: The world of Harlequin. Cambridge U.P. 1963. 


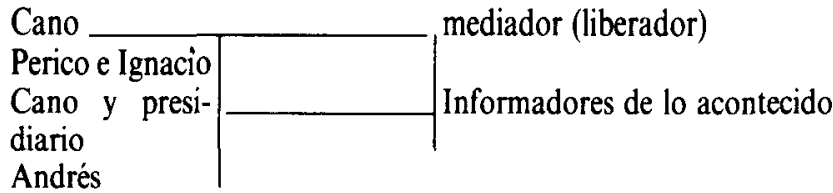

Los personajes de Juan José no son idénticos a los del drama de honor del Siglo de Oro, faltan unos y se añaden otros, que cumplen funciones distintas y que se reflejará estructuralmente en un modelo actancial único (cosa que demuestra una gran simplicidad en la técnica de procesos y conflictos dramáticos de la obra de Dicenta) en forma de triángulo amoroso que suele aparecer, aunque con mayores complicaciones, en el drama del Siglo de Oro: Una tríada de personajes Juan José-Rosa-Paco, ayudados por otros caracteres de la obra y con unos predicados de base específicos (amor, agradecimiento y protección afectiva, rivalidad amorosa, animadversión jerárquica, deseo y afán de estabilidad económica).

Los protagonistas de este conflicto amoroso que configura la estructura superficial de Juan José se caracterizan mediante oposiciones y contrastes que reflejan los diferentes ejes semánticos. Así la caracterización del personaje Juan José se hace mediante oposiciones, no sólo respecto a su antagonista y rival, Paco (centrada en dicotomías «obrero/burgúes», «pobre/ rico"), sino también respecto a Andrés (cuyas diferencias esenciales se basan en el plano afectivo, político y cultural), su amigo, y que teóricamente debería hallarse en una situación semejante a la de nuestro protagonista. Sin embargo, los condicionantes de Juan José son mucho mayores que los de Andrés. La «bondad» del personaje Juan José se concreta en el contraste con ambos, debido a su situación mucho más dificil e injusta socialmente, y también con el contraste final con Cano, delincuente, frente a la honradez de Juan José, a quien sólo las circunstancias le llevan a delinquir, con una finalidad hasta cierto punto justificable, lavar su honra, por lo tanto, sus razones no son materiales, sino espirituales.

Juan José es el personaje que más elementos románticos posee, no sólo por su origen oscuro (aunque la anagnórisis no se plantee), sino por su caracterización: impulsivo y apasionado en su comportamiento, el cual es razonable para los otros personajes que en todo momento demuestran su comprensión y simpatía hacia él. De tal manera que el ya citado origen oscuro, la infancia padecida, la soledad, etc..., crean un héroe muy próximo al melodrama o folletín decimonónico, en quien la hostilidad hacia el mundo en el que vive está fuertemente condicionada por las circunstancias en las que se desenvuelve.

Por su parte la configuración negativa del personaje de Paco sólo se basa en su poder económico, su actitud de «pretendiente» y transgresor de la norma, desestabilizando a la considerada pareja "estable», y también la 
utilización de Isidra - personaje históricamente encasillado también en una conducta negativa - como su mediadora. Por otra parte, la «bondad" de Paco, pues trata con cariño a Rosa, es una actitud que parte de su «status» social. Así, al ser rico no se ve precisado a comportarse mezquinamente y tiene todas las posibilidades de hacer feliz al ser que se encuentra junto a él, cosa que se manifiesta también en Rosa, aunque como personaje que recibe los favores de la riqueza. Por lo tanto parece como si subyaciera en la mente de Dicenta el comunicarnos que las estrecheces económicas conllevan una actitud agresiva, mientras que la opulencia económica permite incluso comportarse bien.

La caracterización de Rosa se produce, al igual que la de los otros personajes, mediante contrastes, aunque éstos tienen un sentido muy distinto a los de Juan José, ya que, como hemos apuntado anteriormente, todo justifica la actuación de Juan José, sólo hay un elemento que justifique la actuación de Rosa: la necesidad material, y aún mitigado al abrazar finalmente la riqueza más que conformarse con no padecer necesidad. Pensamos, respecto al personaje de Rosa, que no tiene un proceso como tal, sino que es a través de la Isidra cuando manifiesta su «realidad» como personaje, ya que tanto con Juan José como con Andrés o Toñuela está coaccionada por una serie de elementos de relación; su rebeldia frente a Juan José (Acto II,7 y en el Cuadro II del Acto III) se canaliza normalmente a través de Isidra - hecho que confirmaría el esquema de aparición del personaje, su estrategia dramática-; muestra de ello es el único enfrentamiento de Rosa y Juan José con un dominio, natural y esperado, de la primera:

JUAN JosÉ.- (Luego de contemplar a Rosa un instante. Con tono desengañado $y$ duro). Rosa, jtú eres mala!

Rosa.--(Con brusquedad). ¡No sé lo que soy, pero carezco de todo, de lo más preciso, y no puedo pasar sin ello; porque sin nada no se pasa! ¡Si tú no me lo das tendré que buscarlo! (JJ, p. 127.)

Este dominio que Rosa mantiene sobre Juan José es esencial para el posterior desarrollo del conflicto dramático personal-social del protagonista; de este modo, la calculada actuación «negativa» de Rosa con respecto a Juan José es utilizada por Dicenta para la creación de un personaje femenino, más o menos verosímil, como puede comprobarse en I,11 donde los «celos» de Rosa al saber que Paco está en la taberna con otras mujeres, es fácilmente convencida por ésta para que se una a ellos. Es notable el hecho de que será la única relación directa Paco-Rosa antes de su vida común; en nuestra opinión esto supone: $\left.1 .^{\circ}\right)$ un perjucio para las connotaciones del personaje Rosa, especialmente su versatilidad; $2 .^{\circ}$ ) una identificación, por parte del lector o espectador (situémonos en las necesidades 
proletarias de 1895 ) con las motivaciones y con el personaje de Juan José; 3..$^{\circ}$ ) un fuerte contraste entre Rosa y Tonuela como consecuencia de los dos puntos anteriores, acentuado por sus profundas diferencias (no sumisa/sumisa, afán burgués/proletaria, inconformista/conformista).

La pareja Andrés-Toñuela se configura de forma muy simple, al igual que se configurara la pareja de graciosos o criados en el teatro del Siglo de Oro español, es decir, como contraste de la pareja de protagonistas, Juan José-Rosa. Estos viven en conflicto, aquéllos en armonia. Pero además los elementos de contraste se perciben individualmente. Cumplen la función de ser los confidentes correspondientes a la pareja protagonista. Es importante la comparación entre Andrés y Juan José, ya que aun teniendo más medios el primero, Juan José alcanza una mayor consideración.

\section{CONCLUSIONES}

La justa valoración de Juan José debe insertarse en el panorama teatral de la época. Muy sucintamente no podemos olvidar autores extranjeros como Tolstoi, Ibsen, Krotopkin, Björson... conocidos en la última década del siglo XIX y que debieron influir en los dramaturgos españoles. A los que habría que añadir, además de Echegaray, ya en progresiva caída a partir de 1890 , toda una serie de autores que preparan el drama de Dicenta. Nos referimos, por una parte, a autores que cultivan el drama realista de crítica social de la clase media como Enrique Gaspar con Las personas decentes (1890) o Pérez Galdós con Realidad (1892) y La de San Quintín (1893). Por otra parte a autores que cultivan el drama social reflejo de la problemática de los trabajadores, como por ejemplo La pasionaria (1893) de Leopoldo Cano, La Dolores (1892) de Felíu Codina, Maria Rosa (1894) de Guimerá o Teresa (1895) de Clarín, que son los antecedentes de Juan José, la cual se diferencia del resto de las obras citadas por exponer con mayor claridad el conflicto de la lucha de clases.

Mas Ferrer ${ }^{28}$ distingue en Juan José entre: $\left.1 .^{\circ}\right)$ una acción o unidad dramática interna, caracterizada por la lucha de clases, conflicto social y justicia social; $2^{\circ}$ ) una unidad dramática externa representada por el amor, los celos y la pasión.

Algunos críticos apenas le dan importancia a lo que hay de social y comprometido en la obra y resaltan la estructura del drama de honor que Juan José tiene. Pero hasta ahora lo que no se había hecho era comprobar minuciosamente esta estructura. Y así, efectivamente, en nuestro breve es-

${ }^{28}$ Vida, Teatro y Mito de Joaquin Dicenta. Diputación Provincial de Alicante, 1978, p. 106. 
tudio hemos constatado la temática calderoniana del honor, su percusión y peculiaridad en Juan José, pero también se pone de relieve el tema social. Finalmente se estudia pormenorizadamente la estructura y los personajes de la obra comparándola a otros modelos, demostrándose que Juan José se crea de una forma específica, tomando algunos rasgos de esos modelos, pero configurándose definitivamente como un modelo estructural diferente. Así, pues, Juan José podrá tener algunas características del drama de honor del Siglo de Oro español (tema del honor, personajes, etc...), pero también en una obra nueva, que implica un nuevo teatro en aquellos momentos, no sólo en cuanto a los contenidos (lo social), sino también en cuanto estructura de la obra. Esta novedad parte de la consideración de que ambas acciones o unidades dramáticas (externa e interna) están ensambladas, por lo tanto, cualquier pretensión de dar primacía a una sobre la otra implica desvirtuar lo primordial y peculiar de la obra, ese ensamblaje.

El carácter nuevo, revolucionario de la obra, puede constatarse a partir de lo que supuso la representación de la obra en su momento (1895), cómo pasó del éxito inicial a la prohibición posterior llevada a cabo por los alcaldes de ciudades como Palma de Mallorca, Mahón, Jaén, Zaragoza, etc..., y también por la desaprobación hecha por numerosos obispos ${ }^{29}$. La conflictividad de la obra ya se había manifestado en el hecho de que la actriz principal de la comedia, la Tubáu, se negara a representar el papel de Rosa. Y no menos significativo es el recibimiento que la prensa de la época le hizo a la obra ${ }^{30}$.

La pretensión de ver en Juan José exclusivamente o, sobre todo, un drama de honor nos parece falso. Al respecto los argumentos expuestos por Mas Ferrer rebatiendo a Garcia Pavón nos parecen acertados. Sirva de muestra un fragmento en el que se comprueba la conciencia de Joaquín Dicenta sobre lo que suponía su polémica obra Juan José:

\footnotetext{
Para los que dudan de la intencionalidad de J. Dicenta y los móviles que le motivaron plasmar una problemática social y de lucha de clases, en Juan José, le remitimos a una entrevista sostenida con Antonio Honeros, poco después de finalizar la obra, a la pregunta del crítico: “Fue seguro al estreno?». Dicenta, anticipándose a los hechos, responde: «No, sabía que mi obra tenía aspectos nuevos, sociales, y que en la Comedia no habia un público muy idóneo. Yo mismo estaba sorprendido ante aplausos tan clamorosos) ${ }^{31}$.
}

\footnotetext{
29 Idem, p. 126.

${ }^{30}$ El estudio de Mas Ferrer muestra ampliamente este aspecto a partir de la p. 121.

"Ídem. p. 118.
} 
Juan Josétuvo una clara lectura en su época, al menos por cierta prensa:

Joaquín Dicenta, pues, ha enarbolado en Juan José la bandera de la igualdad; alrededor de ella, debemos agruparnos todos cuantos jóvenes tengamos fe en un porvenir lleno de grandezas ${ }^{32}$.

Martínez Ruiz en aquellos momentos todavía era un joven radical que veía en la obra y su autor lo siguiente:

Hay en la obra la energía de un filósofo, el empuje de un revolucionario... Sí Juan José no es drama, Juan José es el drama de nuestros días. Es la encarnación, el símbolo de esta sociedad fin de siglo, que se presta a una lucha terrible, que «no sabe cómo ha dudado tanto tiempo»;

Joaquin Dicenta hizo labor de revolucionario; J. Dicenta se ganó con aquel hermoso arranque de independencia las simpatias del pueblo que trabaja y lucha, los aplausos calurosos de la juventud que suspira por la libertad ${ }^{33}$.

Por todo lo dicho es evidente que Juan José fue el drama del proletariado, históricamente fue el símbolo de la lucha de clases de aquellos últimos años del siglo XIX. El mayor error al valorar la obra es mirarla desde la perspectiva actual, exigiéndole planteamientos que hoy podrían ser considerados revolucionarios. Queda claro que la prensa y la crítica literaria española conservadora sólo quisieron ver y sólo ven la estructura externa de Juan José, minusvalorando la estructura interna de la obra.

32 Rafael Delorme: «El socialismo en el Teatro" en El Pais, 31 de octubre de 1895.

${ }^{33}$ Martínez Ruiz: "Crónica» en El Progreso, 15 de febrero de 1898. Esta y la anterior cita están tomadas de Mas Ferrer: op. cit., pp. 132 y 133. 